\title{
Ultrashort pulsed barrier discharges and applications*
}

\author{
Ken Okazaki ${ }^{\ddagger}$ and Tomohiro Nozaki \\ Department of Mechanical and Control Engineering, Tokyo Institute of Technology, \\ 2-12-1, O-okayama, Meguro-ku, Tokyo 152-8552, Japan
}

\begin{abstract}
Atmospheric pressure nonequilibrium plasmas have made a recent remarkable progress in formation techniques including atmospheric pressure glow discharge (APG), dielectric barrier discharge (DBD), corona discharge, surface discharge, ultrashort pulsed discharge, etc., and are expanding their applications into the field of energy and environment as well as material conversion processes. This paper will especially focus on a large improvement of DBD by combining it with squared ultrashort high voltage pulses and various applications.
\end{abstract}

\section{INTRODUCTION}

Application of atmospheric pressure nonequilibrium plasma, now exclusively produced by APG [1-3] and DBD [4-5], is spreading out into various engineering fields of not only material processing, but also energy and environment due to its special advantages of forming a highly reactive plasma at almost room temperature with low energy consumption using simple reactor system under atmospheric pressure [6-7]. This review article pays special attention to a recent development of those plasmas and their applications including our own recent work.

\section{ADVANTAGES OF PULSED DIELECTRIC BARRIER DISCHARGE}

The conventional DBD using an ac high voltage has a relatively low instantaneous energy input, where only dispersed spike-like currents imposed on the sinusoidal current waveform can enter into the reacting plasma field as shown in Fig. 1a. On the other hand, high voltage pulses enable a very high instantaneous energy input concentrated at the sharp voltage rising and falling as shown in Fig. 1b, and this advantage becomes more dominant using high-frequency ultrashort pulses. This instantaneous highenergy input will enhance the formation efficiency of highly energetic electrons resulting in the efficient formation of key radical species. We combined this pulsed DBD with a cylindrical corona type electrode configuration to realize a simple reactor system and then applied it to various processes; (a) efficient generation of ozone, (b) chemical vapor deposition of $\mathrm{SiO}_{2}$ films, (c) simultaneous removal of $\mathrm{NO}_{\mathrm{X}}, \mathrm{SO}_{\mathrm{X}}$ and fly ash particles from actual coal combustion gas, (d) direct synthesis of methanol from methane and water vapor mixture.

\footnotetext{
*Lecture presented at the $15^{\text {th }}$ International Symposium on Plasma Chemistry, Orléans, France, 9-13 July 2001. Other presentations are presented in this issue, pp. 317-492.

${ }^{\ddagger}$ Corresponding author
} 


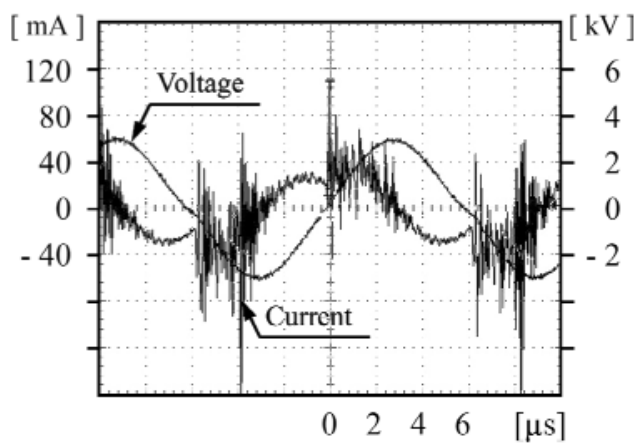

(a) Sinusoidal $80 \mathrm{kHz}$

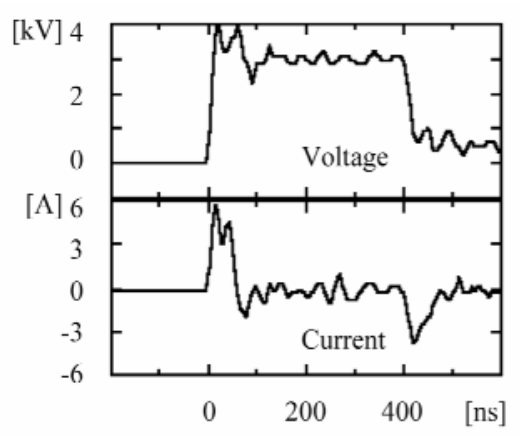

(b) Ultrashort pulsed voltage

Fig. 1 Voltage and current waveforms.

\section{APPLICATIONS}

\section{Efficient generation of ozone}

We have applied squared high-voltage pulses to the DBD ozonizer instead of usual high-voltage ac, and much higher ozone yield of $250 \mathrm{~g} / \mathrm{kWh}$ has been obtained from dried pure oxygen even for a high ozone concentration $\left(40 \mathrm{~g} / \mathrm{m}^{3}\right)$ as shown in Fig. 2 [8,9]. The highly reactive nonequilibrium condition in this pulsed DBD has two advantages; the effective generation of high-energy electrons and minimizing joule losses to avoid excess temperature increase in microdischarges. And then, efficient generation of copious amount of atomic oxygen as well as suppression of thermal decomposition of once-produced ozone has been simultaneously realized, leading to efficient ozone generation. Further, we are now investigating energy distribution and heat transfer mechanisms in DBD and APG for further optimization of various applications [10-12].

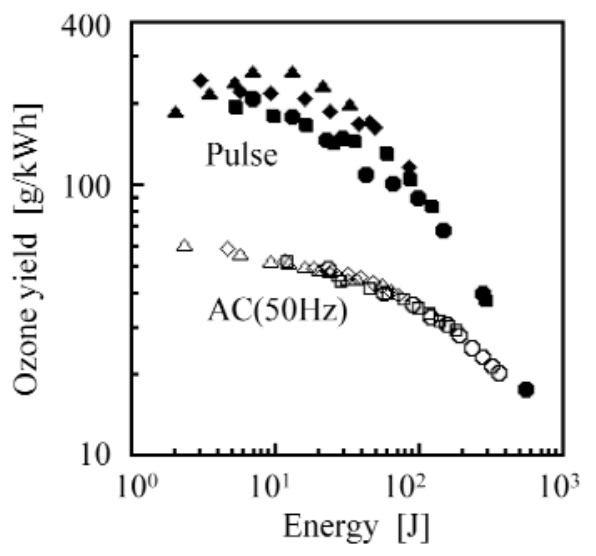

Fig. 2 Enhancement of ozone yield by squared high-voltage pulses.

\section{Chemical vapor deposition of $\mathrm{SiO}_{2}$ thin films}

Nonequilibrium plasma processes using pulsed DBD have been applied to atmospheric pressure CVD to form $\mathrm{SiO}_{2}$ thin films in tetraethlorthosilicate [TEOS: $\left.\mathrm{Si}\left(\mathrm{OC}_{2} \mathrm{H}_{5}\right)\right] / \mathrm{O}_{2}$ system [13]. It has been known that, unlike conventional low-pressure plasma processes using $\mathrm{SiH}_{4}$, unique characteristics of TEOS 
provide excellent step coverage and void-free filling over gaps of high aspect ratio under atmospheric pressure $[14,15]$. In addition, various film qualities can be dramatically improved by adding oxidative agents into the reaction system, leading to atmospheric pressure thermal CVD using TEOS $/ \mathrm{O}_{3}$ mixture. On the other hand, we investigated DBD-assisted remote CVD to form $\mathrm{SiO}_{2}$ thin film from TEOS/O mixture. SEM micrographs are shown in Fig. 3a, ac $(50 \mathrm{~Hz})$ high voltage, and 3b, square-pulsed high voltage. We successfully realized $\mathrm{SiO}_{2}$ film deposition in both conditions, however, excellent film quality was obtained only when applying square-pulsed voltage as shown in Fig. 3b. The effective generation of active oxygen species including ozone would have contributed to the production of optimum precursors for $\mathrm{SiO}_{2}$ film deposition in the gas phase. The film properties were compared to those obtained in the atmospheric pressure thermal CVD using TEOS $/ \mathrm{O}_{3}$ mixture at a substrate temperature of $650 \mathrm{~K}$. DBD-assisted remote CVD using high-voltage pulses was superior to the conventional method in terms of deposition rate and step coverage characteristics.

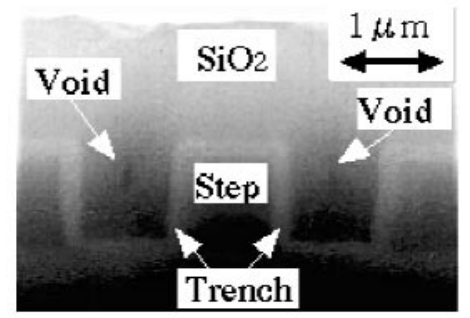

(a) ac $50 \mathrm{~Hz}$

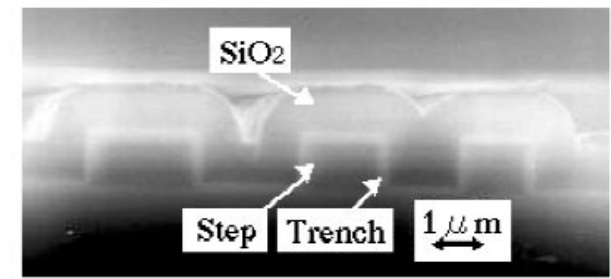

(b) Ultrashort square-pulsed voltage

Fig. 3 SEM micrographs of $\mathrm{SiO}_{2}$ film deposited on trenches having an aspect ratio of 0.8 .

\section{Simultaneous removal of $\mathrm{NO}_{\mathbf{X}}, \mathrm{SO}_{\mathrm{X}}$, and fly ash in pulverized coal combustion}

Simultaneous removal of $\mathrm{NO}_{\mathrm{X}}, \mathrm{SO}_{\mathrm{X}}$, and fly ash particles from actual pulverized coal combustion flue gas has been successfully realized applying the pulsed DBD to a semi-wet type reactor with a water film on the inner wall of the glass tube as shown in Fig. 4. As a result, $92 \%$ of $\mathrm{NO}_{\mathrm{X}}, 99 \%$ of $\mathrm{SO}_{\mathrm{X}}$ (Fig. 5),

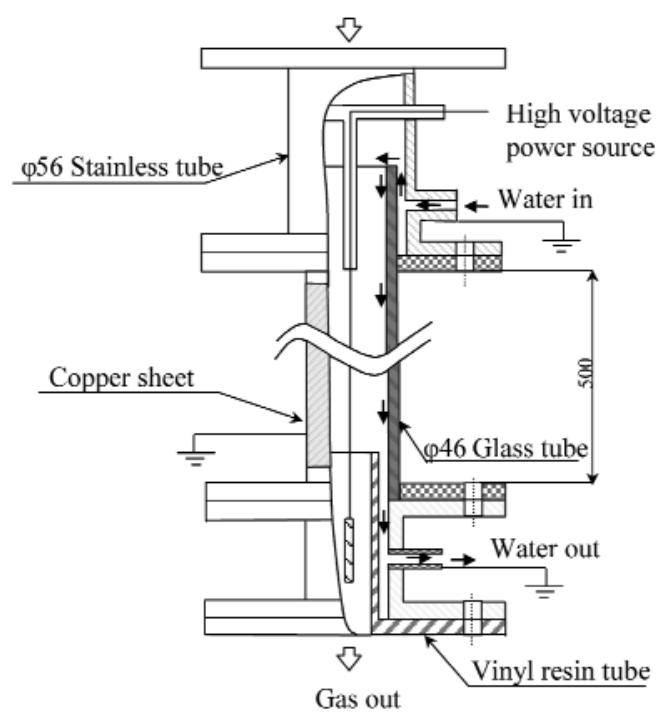

Fig. 4 Semi-wet type pulsed DBD reactor for the effective gas clean-up in pulverized coal combustion. 
and $96 \%$ of fly ash particles (Fig. 6) have been simultaneously removed from the flue gas [16,17]. It has been confirmed that the $\mathrm{NO}_{\mathrm{X}}$ removal efficiency of $60 \%$ shown in Fig. 5 can be enhanced to $92 \%$ by expanding the residence time to $12 \mathrm{~s}$. The high removal efficiency of $\mathrm{NO}_{\mathrm{X}}$ even for a high oxygen concentration of about $15 \%$ can be attained due to the sequent processes of oxidation of $\mathrm{NO}$ to $\mathrm{NO}_{2}$ and its absorption into the water film. The semi-wet type reactor has an excellent performance for the removal of $\mathrm{SO}_{\mathrm{X}}$, while it is almost impossible using a dry-type reactor even with intensive discharges. The high collection efficiency of fly ash particles can also be attained by this system working as an electrostatic precipitator during dc high-voltage pulses. The water film should have enhanced the collection efficiency by suppressing re-entrainment of particles.

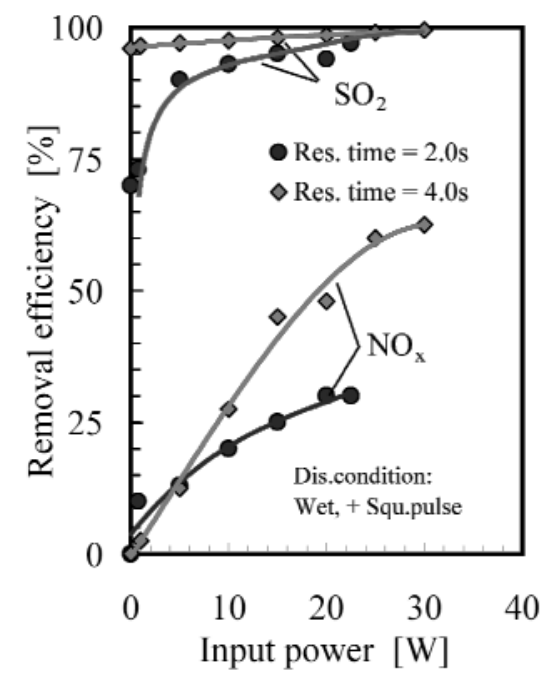

Fig. 5 Simultaneous removal of $\mathrm{NO}_{X}$ and $\mathrm{SO}_{X}$ from pulverized coal combustion gas.

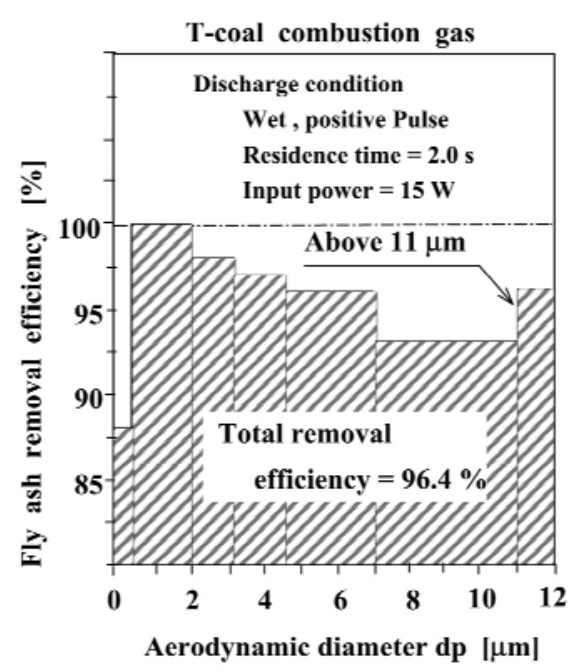

Fig. 6 Removal efficiency of fly ash particles for various particle sizes. 


\section{Direct synthesis of methanol from methane and water vapor mixture}

By applying an ultrashort pulsed DBD to a thin glass tube reactor as shown in Fig. 7, direct synthesis of methanol from methane and water-vapor mixture has been successfully realized under atmospheric pressure [18,19], although such kind of reaction with large increase of free energy can never occur through usual thermochemical processes. Two key radical species of $\mathrm{CH}_{3}$ and $\mathrm{OH}$ can be effectively formed by this method, and the inner wall of a very thin glass tube having $1.8 \mathrm{~mm}$ diameter might have played a significant role of quenching as a third-body to avoid redissociation or further oxidation of methanol. Even in a result of one-pass reaction, significantly high maximum values of methanol yield and selectivity of $0.8 \%$ and $7.5 \%$, respectively, have been obtained for the water vapor content of about $50 \%$, shown in Fig. 8. The value of methanol yield was more than ten orders of magnitude higher than the thermodynamically equilibrium one. Based on our theoretical investigation, the generation of $\mathrm{CH}_{3}$ by electron impact was decreased with the further increase of water vapor content due to the increasing effect of electron attachment. Furthermore, a large amount of atomic hydrogen produced by decomposition of $\mathrm{H}_{2} \mathrm{O}$ as well as $\mathrm{CH}_{4}$ remarkably consumed $\mathrm{OH}$ radicals through recombination processes, limiting the water vapor content in the feed gas by $50 \%$ for efficient production of methanol.
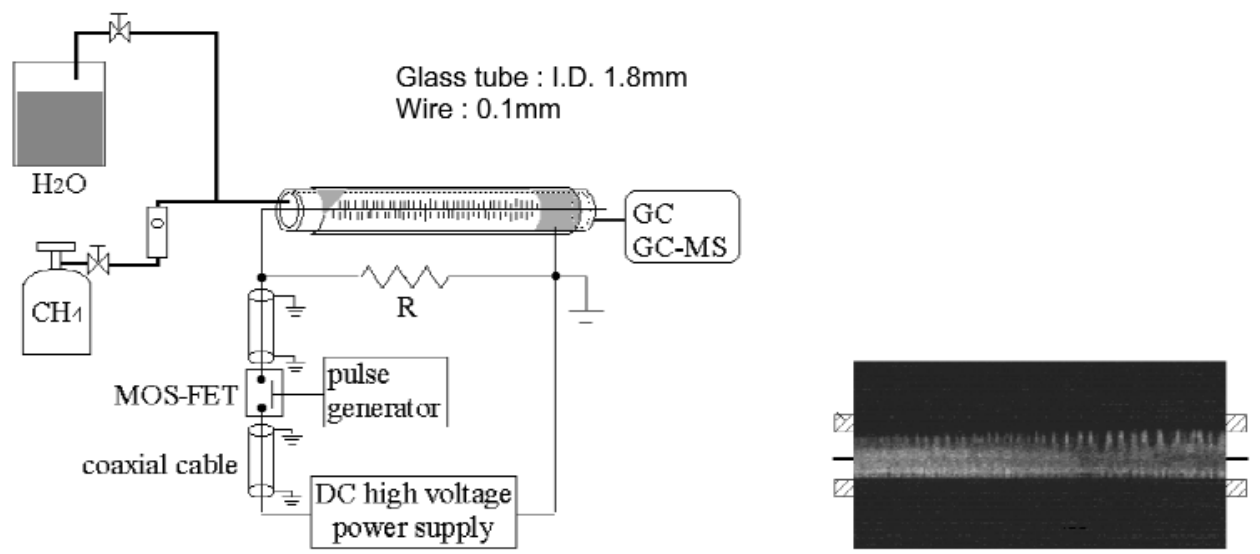

Fig. 7 Ultrashort pulsed DBD reactor configured by thin glass tube and discharge image.

Fig. 8 Methanol yield.

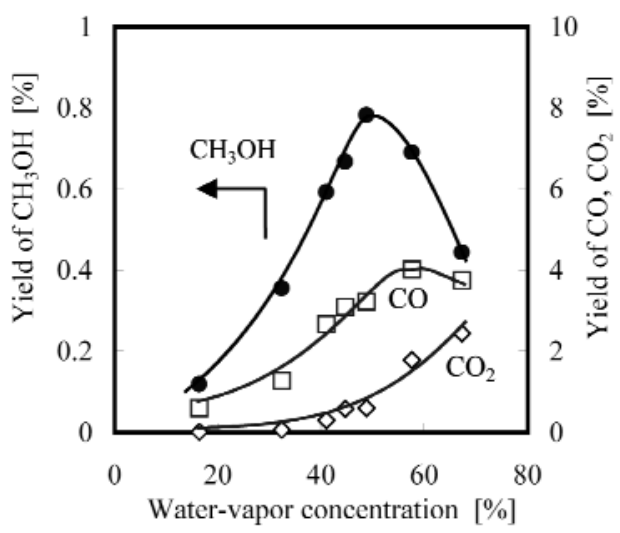




\section{CONCLUDING REMARKS}

A new technique to form highly reactive nonequilibrium plasmas at atmosphere has been developed by using ultrashort pulsed dielectric barrier discharge, and various applications based on our recent work have been briefly reviewed. Industrial application of atmospheric-pressure nonequilibrium plasmas will continue to grow into various fields of not only material processing, but also energy and environmental safe technologies, however, there is very little understanding about complicated fundamental phenomena related directly to transient and unsteady situations that are essential to create the nonequilibrium condition even at high pressures. Also in the practical viewpoint, low energy cost is the critical issue for the widespread use of this technology. Therefore, further intensive studies, including both macroscopic and microscopic aspects, should be necessary for the best process design and additional novel applications in the future.

\section{ACKNOWLEDGMENTS}

The authors wish to thank Associate Prof. Kazuhiro Ishimaru of Gifu National College of Technology for very intensive discussions and contributions to this work.

\section{REFERENCES}

1. S. Kanazawa, M. Kogoma, T. Moriwaki, S. Okazaki. J. Phys. D: Appl. Phys. 21, 838-840 (1998).

2. F. Massines, A. Rabehi, P. Decomps, R. B. Gadri, P. Segur, C. Mayoux. Appl. Phys. 83 (6), 2950-2957 (1998).

3. S. F. Miralai, E. Monette, R. Bartnikas, G. Czeremuszkin, M. Latreche, M. R. Wertheimer. Plasmas Polym. 5 (2), 63-77 (2000).

4. I. V. Gibalov and J. G. Pietsch. Appl. Phys. 33, 2618-2636 (2000).

5. J. Kitayama and M. Kuzumoto. Appl. Phys. 30, 2453-2461 (1997).

6. U. Kogelschatz, B. Eliasson, W. Egli. Invited Plenary Lecture ICPIG XXIII 1-20 (1997).

7. K. Okazaki and T. Watanabe. Annual Review of Heat Transfer, C. L. Tien (Ed.), Chap. 2, pp. 25-100, Begell House, Inc. (1999).

8. K. Ishimaru and K. Okazaki. Microscale Thermophys. Eng. 1 (2), 159-169 (1997).

9. B. Eliasson, M. Hirth, U. Kogelschatz. Appl. Phys. 20, 1421-1427 (1987).

10. T. Nozaki, Y. Unno, Y. Miyazaki, K. Okazaki. J. Phys. D: Appl. Phys. 34 (16), 2504-2511 (2001).

11. T. Nozaki, Y. Miyazaki, Y. Unno, K. Okazaki. J. Phys. D: Appl. Phys. 34 (23), 3383-3390 (2001).

12. T. Nozaki, Y. Miyazaki, Y. Unno, K. Okazaki. Proc of the $15^{\text {th }}$ Int. Symp. on Plasma Chemistry (ISPC-15), July, Orleans, France 1, 77-83 (2001).

13. K. Ishimaru and K. Okazaki. Thermal Sci. Eng. 7 (5), 11-20 (1999).

14. M. Matsuura, Y. Hayashida, H. Kotani, H. Abe. Jpn. J. Appl. Phys. 30 (7), 1530-1538 (1991).

15. S. Wickramanayaka, A. Matsumoto, Y. Nakanishi, N. Hosokawa, Y. Hatanaka. Jpn. J. Appl. Phys. 33 (1-6A), 3520-3527 (1993).

16. K. Okazaki, A. Mizuno, K. Shimizu, T. Niwa. Proc. of the JSME-ASME Int. Conf. on Power Engineering 2, 103-108 (1993).

17. H. H. Kim, K. Tsunoda, K. Shimizu, S. Tanaka, T. Yamamoto, A. Mizuno. J. Adv. Oxidation Technol. 4 (3), 347-351 (1999).

18. T. Kishida, N. Yamada, T. Nozaki, K. Okazaki. Thermal Sci. Eng. 7 (3), 1-9 (1999).

19. K. Okazaki and T. Nozaki. Thermal Sci. Eng. 7 (6), 109-114 (1999). 